\title{
Interaction between Coastal Development and Inland Estuarine Waterways at the Short-Medium Timescale
}

\author{
Griffith Centre for Coastal Management \\ Gold Coast Campus \\ Griffith University \\ Queensland 4222, Australia
}

Hamid Mirfenderesk and Rodger Tomlinson

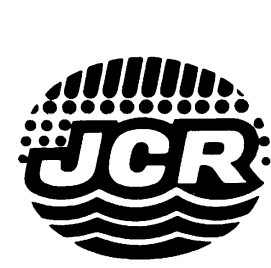

\begin{abstract}
MIRFENDERESK, H. and TOMLINSON, R., 2009. Interaction between coastal development and inland estuarine waterways at the short-medium timescale. Journal of Coastal Research, 25(4), 969-980. West Palm Beach (Florida), ISSN 0749-0208.

This article highlights the impact of tidal inlet modification on the evolution of inland estuarine waterways at the short-medium timescale. The study area is the Nerang River estuarine system located on the east coast of Australia. This estuary has been affected by a range of developments, including stabilization of its tidal entrance. This study is mainly focused on quantifying the tidal regime change and potential morphological and ecological implications resulting from these changes. To this end, the study started with field data collection and numerical modelling of the study area. The results of harmonic analysis showed that the Nerang Estuary responds nonlinearly to tidal forcing and is dominated by frictional forces. Analysis of water level and current time histories showed a mixed, predominantly semidiurnal, and flood-dominant tidal regime within the estuary. It also showed strong asymmetry of tide along the estuary. At the second stage of the study, historical data of the study area were analyzed and compared with the recently collected data. The purpose of this stage of the study was to understand the evolution of the estuary as a result of the changes at its entrance over the past 20 years. Variations in the ratio of amplitudes from M4 to M2 demonstrate that the Nerang Estuary nonlinear response to tidal forcing has reduced over the past 20 years. Analysis of historical data also suggests that the estuary has become less flood-dominant over the past 20 years, and as a result, the balance between tide-influenced sediment infilling and sediment flushing of the estuary during freshwater flooding events may have shifted toward transporting more sand out of the estuary.
\end{abstract}

ADDITIONAL INDEX WORDS: Tidal, asymmetry, semidiurnal, nonlinear.

\section{INTRODUCTION}

Tidal entrances play an important role in the overall dynamics of an estuary. Change in resistance against flow at the entrance has an impact on tidal amplitude and phase (Hinwood and Mclean, 2000) and, consequently, on sediment flux into and out of the estuary, flow velocity, and the erosion-deposition regime in the estuary. Tidal entrance behaviour influences the nonlinear interaction between tidal constituents, resulting in changes in asymmetric characteristics of the tide and, consequently, influences the morphology, water quality, and ecology of the estuary. The Nerang River tidal entrance has undergone substantial change over the past 20 years. The most significant change has been the construction of the Gold Coast Seaway that connects the Pacific Ocean to the estuary of the Nerang Riverreferred to as the Nerang Estuary. The Seaway, which was constructed in 1985 along with Wave Break Island, replaced a natural shallow opening located approximately $500 \mathrm{~m}$ north of the current position of the Gold Coast Seaway. The construction of the Seaway was followed by the dredging of a navigation channel between the Seaway and Sundale Bridge approximately 5 $\mathrm{km}$ south of the Seaway at the mouth of the Nerang River. Figures 1 and 2 show this entrance before and after construction

DOI: 10.2112/06-0741.1 received 2 July 2008; accepted in revision 28 July 2008. of the rock walls, respectively. The photos clearly show that conveyance of this tidal entrance has been modified significantly as a result of this development. The original entrance was a narrow and shallow opening (this opening occasionally closed as a result of bar building), whereas the artificial navigational channel (Seaway) was $250 \mathrm{~m}$ wide and $6 \mathrm{~m}$ deep. The impact of this change on the Nerang River system has been complicated by the substantial scour that Seaway experienced during the past 20 years. A recent bathymetry survey by the Queensland Department of Transport (in 2005) showed that the average depth had increased to $11 \mathrm{~m}$. Increase in tidal prism associated with changes in the Broadwater basin can be regarded as a reason for the high degree of scour. In some areas of the entrance, depth had increased to $20 \mathrm{~m}$.

This study initially focused on providing an in-depth understanding of the tidal dynamics of the study area. To this end, the study started with field data collection and numerical modelling of the Nerang Estuary. The measured and modelled tidal data were analyzed to resolve the amplitude and phase of main tidal constituents. The second stage of the study was dedicated to examination of available historic tidal data and aimed at resolving the evolution of the tidal regime of the Nerang Estuary during the past 20 years. This work was the first step in a series of studies with a final goal of providing an understanding of the ecological processes and 


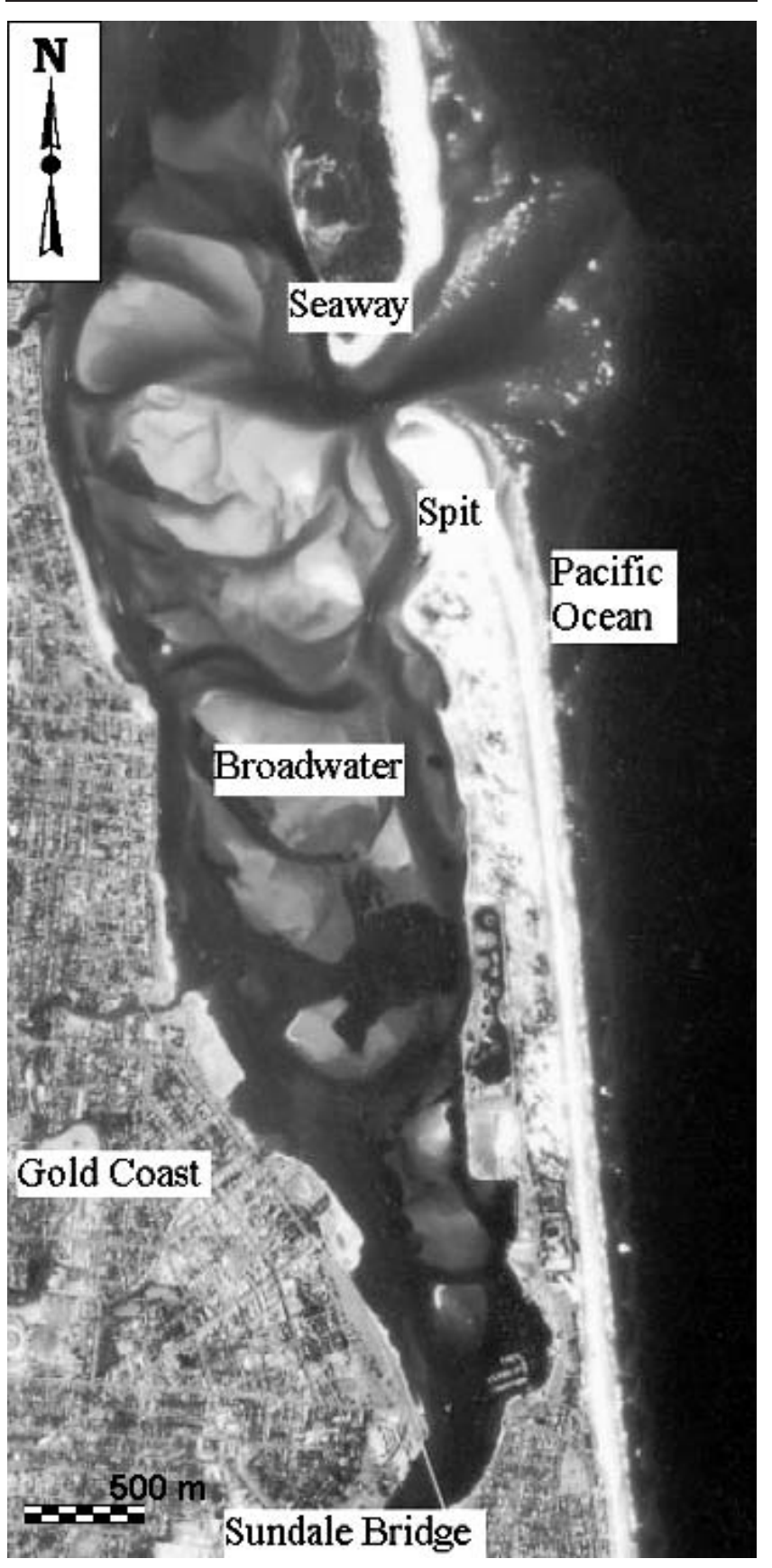

Figure 1. Gold Coast Seaway area in 1980.

sediment-transport regime at the study area and their evolution in the past two decades.

At the time of construction of the Seaway, the Queensland Harbours and Marine Department conducted field-data collection and continued this exercise for a few years after the completion of the new tidal entrance (Broadbent, 1987). That study had a time domain analysis focus, and therefore, some of the impacts of the development on the nonlinear response of the Nerang Estuary were not fully explored. In contrast,

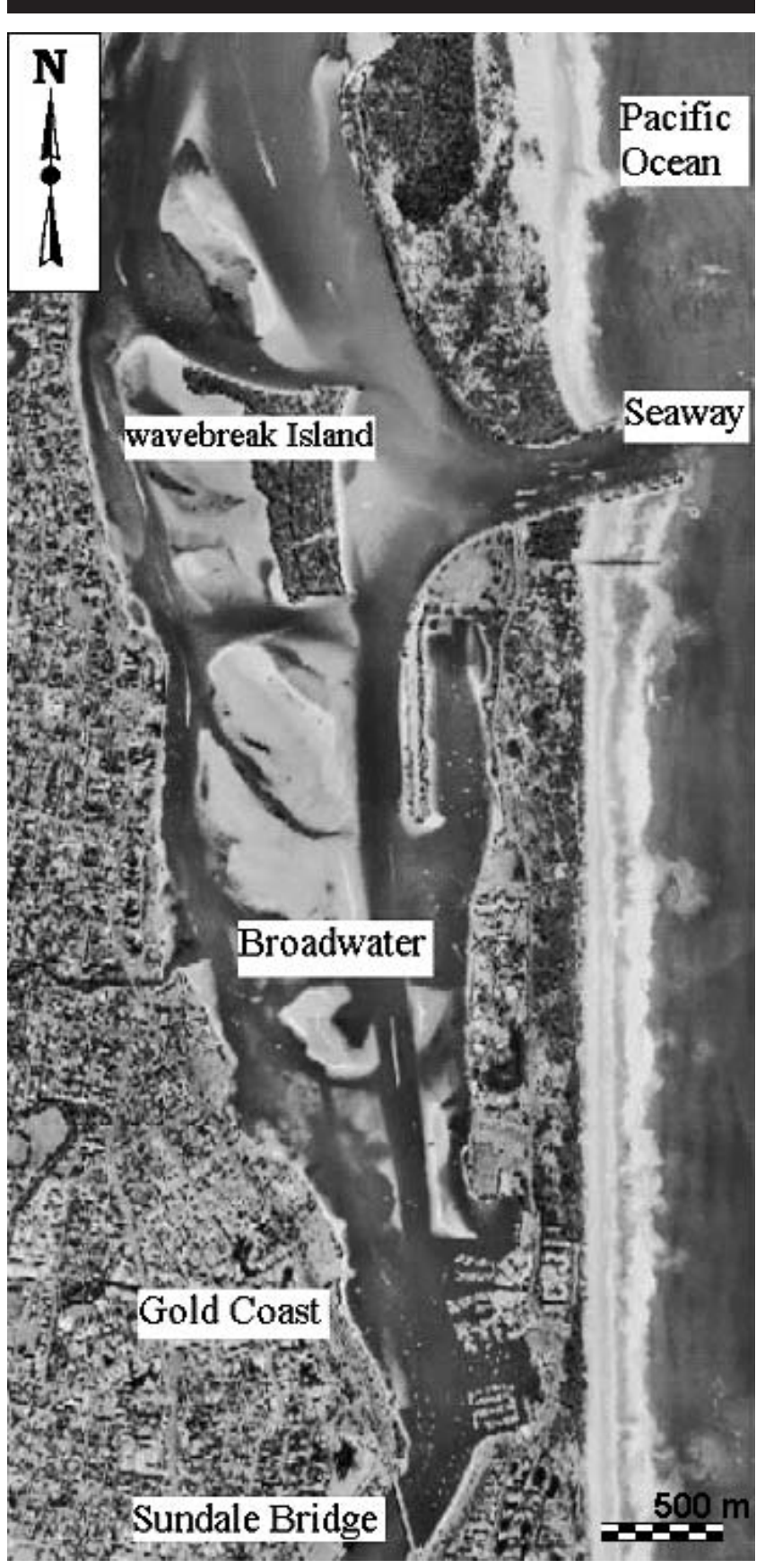

Figure 2. Gold Coast Seaway in 2005. For a color version of this figure, see page 930 .

this study focused on a frequency domain analysis and highlights variations in the nonlinear response of the estuary to tidal forcing and its possible morphological/ecological consequences within the estuary.

\section{STUDY AREA}

Figure 3 shows the extent of the study area. The Nerang Estuary is located in the southeast corner of Queensland, 


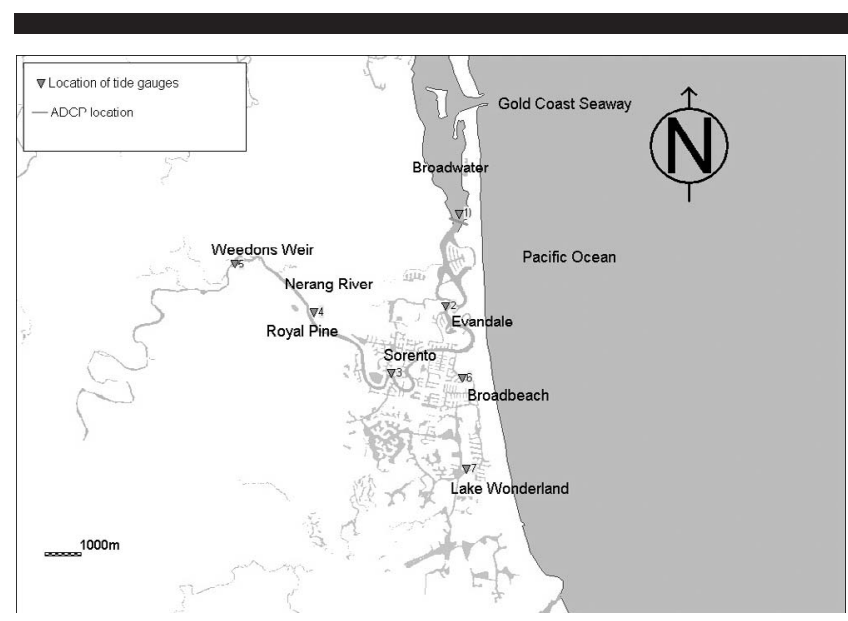

Figure 3. Layout of the study area and approximate locations of the measurement stations.

Australia $\left(28^{\circ} 1^{\prime} 3^{\prime \prime} \mathrm{S}, 153^{\circ} 24^{\prime} 35^{\prime \prime} \mathrm{E}\right)$. It drains runoff from the Nerang River catchment into a coastal water body named the Broadwater. The Broadwater is connected to Pacific Ocean via the Seaway, which is regarded as the main tidal entrance for the Nerang Estuary. The depth of the estuary varies between $8 \mathrm{~m}$ (at lower reaches of the estuary) and close to 0.5 $\mathrm{m}$ at its tidal limit. Tidal and freshwaters of the Nerang River are separated by the Weedons Weir, approximately $23 \mathrm{~km}$ upstream of the mouth of the River. The Hinze Dam, located $37 \mathrm{~km}$ upstream of the river mouth, regulates freshwater inflow into the estuary. Base flow of the Nerang river is negligible for most of the year. The main portion of the catchment rainfall occurs during the summer period in a few heavy storm events. Hinze Dam usually absorbs all the runoff resulting from these storms. There have been only a few spillages from the Hinze Dam during the past 10 years. The catchment includes various land uses. The upper reaches of the Nerang River are covered by dense bush, whereas lower reaches are heavily urbanized. Urbanization of the Nerang floodplain has partly been in the form of canal estates. Some of these canal estates are tidal and have resulted in an increase in the tidal prism of the Nerang Estuary.

\section{METHODS}

This study involved four sections:

(1) Collection of water level, flow velocity, salinity, and temperature data to provide a data set for model calibration;

(2) Development of a calibrated tidal model of the study area to provide an insight into the hydrodynamic behaviour of the Nerang Estuary and to identify important nonlinear mechanisms within the estuary;

(3) Examination of historical tidal variation at the study area to identify any changes in tidal regime during the past 20 years resulting from the construction of the Gold Coast Seaway; and

(4) Discussion about the likely effects of the tidal regime evolution on the ecological and morphological process at the study area.
Table 1. Measurement stations.

\begin{tabular}{clc}
\hline \hline Station No. & \multicolumn{1}{c}{ Station Name } & Distance from Mouth $(\mathrm{km})$ \\
\hline 1 & Nerang River Mouth & 0 \\
2 & Evandale & 4.5 \\
3 & Sorrento & 12 \\
4 & Royal Pine & 17 \\
5 & Nerang Township & 22 \\
6 & Broadbeach & 9 \\
7 & Lake Wonderland & 13 \\
\hline
\end{tabular}

\section{Data Acquisition}

The main equipment used in this study included

- Four CTD350 Greenspan gauges, measuring absolute pressure, conductivity, temperature;

- Three CTD310 Greenspan gauges, capable of measuring absolute pressure and temperature; and

- $1200 \mathrm{kHz}$ vessel-mounted Acoustic Doppler Current Profiler (ADCP), capable of measuring flow velocity in three dimensions.

\section{Water Elevation}

All the levels mentioned in this article were based on Australian Height Datum. Measurements were performed at the seven stations shown in Table 1.

The recording time interval for the gauges was set to 15 minutes, with an averaging interval of 10 seconds (to minimize the impact of ripples, wind-generated waves, localized boat wash, etc.).

The sensor sampled the water level at a rate of 1 sample every 2 seconds. The data record span for stations 1 and 4 was 150 days, and for the rest, 35 days, providing an adequate time period for resolving the primary tidal constituents at each site. Because these gauges measured absolute pressure, the water pressure readings were corrected for variations in atmospheric pressure once the data were downloaded from each gauge. Data obtained from the Bureau of Meteorology station at Seaway were used to make atmospheric pressure corrections. Conductivity and temperature data were collected simultaneously with water level measurements. These data were used to correct the effects of salinity and temperature on measured pressure. To this end, conductivity data were first converted to salinity, using the United Nations Educational, Scientific and Cultural Organization Practical Salinity Scale, and then, the density of water was calculated based on the calculated salinity and the measured temperature. Measurements showed that density variations within the water column were minor at all station sites during normal conditions. This situation could be attributed to the strong mixing processes at the measurement sites. On this basis, density variation inside the water column was not applied to the readings. To adjust the measured water level to a known vertical datum, the tidal gauges were surveyed relative to benchmarks. The result from each gauge was a time series, representing the variations in water surface elevation relative to the Australian Height Datum, which is a standard vertical reference representing mean sea level in the region. Figure 4 depicts the time series of tide and residual variations at the mouth 


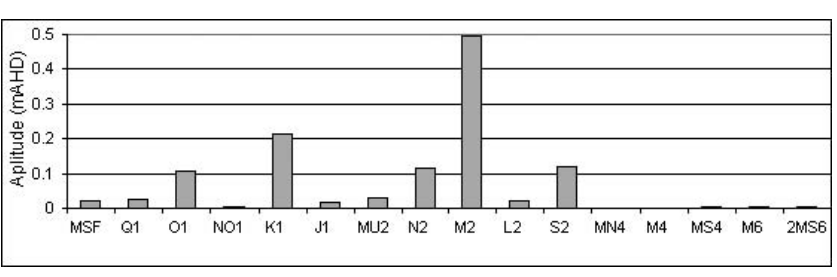

Figure 4. Tidal constituents at station 1 (amplitude).

of the Nerang River during an arbitrary 28-day period, covering both spring and neap tide periods.

To quantify the tidal characteristics of the study area, a frequency domain analysis was carried out for the measured tidal time series. The purpose of tidal analysis was to determine the amplitude and phase of the individual cosine waves, each of which represented a tidal constituent. Tidal harmonic analysis of water level and current speed was carried out using the Mike21 (DHI, 2005) software platform, which is based on the Institute of Ocean Science (IOS) tidal package methodology. Figure 4 depicts amplitude and phase for the 16 tidal constituents at the mouth of the Nerang Estuary. These constituents were derived from a 35-day time series of waterlevel variations at the measurement station. The dominant diurnal tides were $\mathrm{K} 1$ and $\mathrm{O} 1$ constituents, with $\mathrm{K} 1$ having an amplitude 2.5 times greater than 01 . M2 was the dominant semidiurnal constituent, with an amplitude 4 times greater than either the N2 or S2 constituents.

\section{Gurrent Measurements}

A broadband, $1200 \mathrm{kHz}$ Acoustic Doppler Current Profiler (ADCP) was used for collecting current velocity data within the study area. The ADCP measurement was conducted over a full tidal cycle at a cross section from tidal station 1 (Figure 3 ). The boat repeatedly navigated along this cross section (175 times), with the ADCP continuously collecting current data. The ADCP was interfaced with a differential Global Positioning System (GPS) receiver. Clock synchronization between the GPS and the computer, which controlled the ADCP, allowed accurate positioning of the ADCP output data. The ADCP was oriented to look downward into the water column and was operated in bottom-tracking mode, i.e., velocities were measured with respect to the bed. The first bin was $0.8 \mathrm{~m}$ below the transducer, and the bin length was $0.5 \mathrm{~m}$. The extrapolations of velocity into the surface layer and the layer at the bed were conducted automatically by the software that operated the instrument. The instrument was mounted to a mast, which was rigidly attached to a small survey vessel. This exercise provided a three-dimensional flow field along this cross section. Figure 5 shows the discharge (calculated from the measured velocity flow field), the discharge calculated by a numerical model (as explained in the "Data Analysis and Discussion" section), and the water level variation at the measurement station. Discharge associated with ebb tide was taken to be positive and that of flood tide was taken to be negative. Figure 5 shows that, for the period of measurement, the ebbing phase (during high tide)

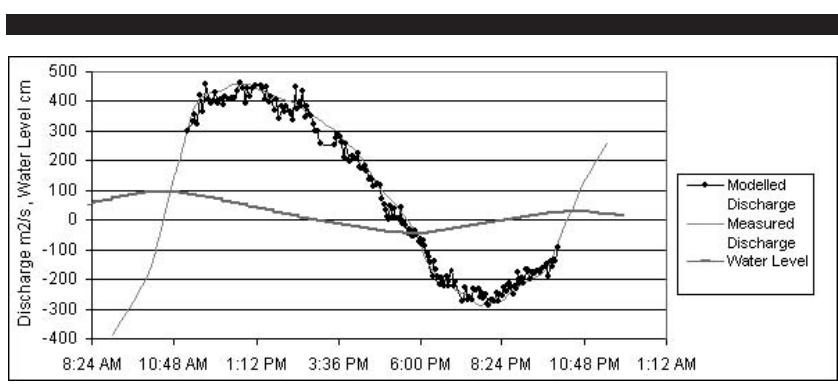

Figure 5. Discharge and water level variations over a tidal cycle.

was approximately 7 hours, and the flooding phase (during low tide) was approximately 5 hours. The measurement also shows that low, slack water lagged behind the maximum ebb discharge by 5 hours (during a high tide), and high, slack water lagged behind the maximum flood tide by 2.5 hours (during the subsequent low tide). Simulated water level and discharge variations (using the numerical model described in the "Data Analysis and Discussion" section) confirmed the general characteristics that can be observed in Figure 5.

Figure 6 shows the horizontal-velocity distribution during

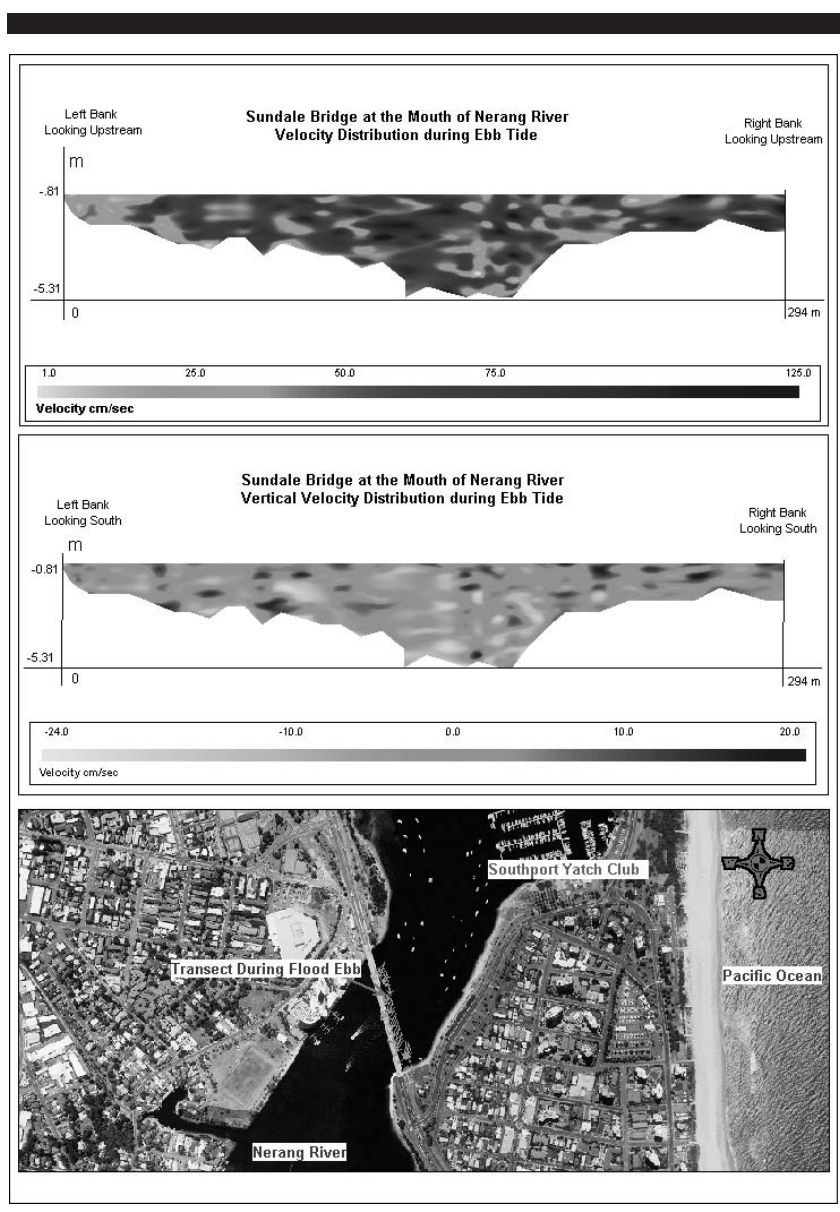

Figure 6. Flow velocity distribution during ebb tide. For a color version of this figure, see page 931 . 


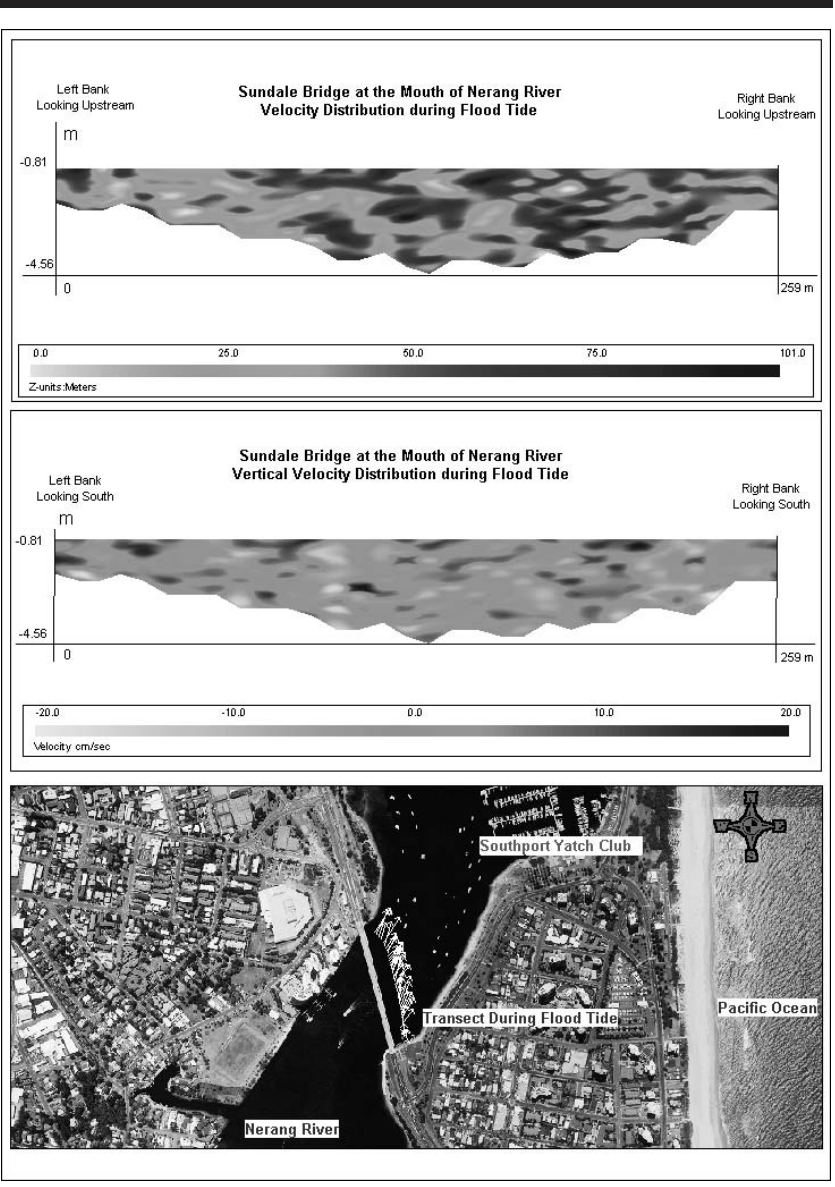

Figure 7. Flow velocity distribution during flood tide. For a color version of this figure, see page 931.

peak ebb tide at tidal station 1 . Horizontal velocity varied between 0 and $1.25 \mathrm{~m} / \mathrm{s}$. Vertical-velocity distribution indicated strong mixing processes with eddies at various length scales were active in this cross section. Vertical velocity at this cross section varied between -0.25 and $0.2 \mathrm{~m} / \mathrm{s}$. Figure 7 shows the horizontal-velocity distribution during peak flood tides (at the subsequent low tide) at the same location. Horizontal velocity varied between 0 and $1 \mathrm{~m} / \mathrm{s}$. Visual inspection of the vertical-velocity distribution (Figure 7) implies processes with length scales being active at the cross section. Vertical velocity at this cross section varied between -0.2 and $0.2 \mathrm{~m} / \mathrm{s}$ during low flood tide.

\section{Numerical Modelling}

A numerical hydrodynamic model (using the MIKE11 software package) was developed for the simulation of tidal flow within the Nerang Estuary. The hydrodynamic module of MIKE11 solved the vertically integrated equations of conservation of mass and momentum (Saint Venant) equations.

The equations were solved by implicit, finite difference techniques. The solution to these equations was based on the assumption that the wave lengths were large compared with the

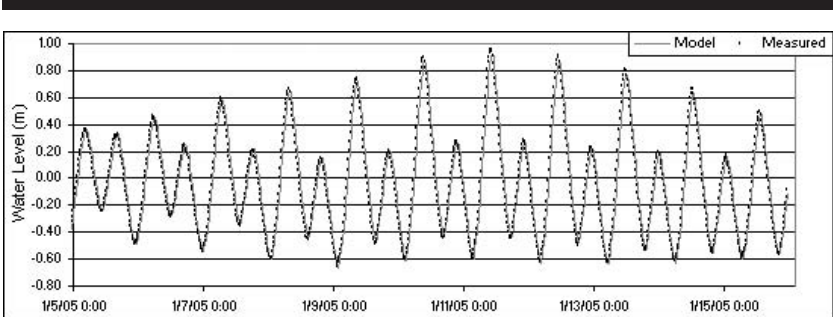

Figure 8. Comparison between measured and simulated water level at station 3 (Seven Oak).

water depth, implying that the flow was always parallel to the bottom, that vertical accelerations were negligible, and that pressure variation along the vertical was hydrostatic. The model can be applied to branched and looped networks and to quasi two-dimensional flow simulations on floodplains. Given the configuration of the Nerang Estuary, which is in the form of a system of narrow natural and artificial channels, this modelling tool was regarded as appropriate for this exercise.

Freshwater inflow into the estuary is insignificant for most of the year and because of strong mixing processes, the estuary usually remains well mixed. Random salinity measurement within the study area confirmed this and showed that the baroclinic contribution to the tidal elevations is negligible. On this basis, the numerical modelling for this study was based on the assumption of a barotropic condition. Bottom friction was modelled using the Manning coefficient, and the model was fully dynamic and driven by the tide. This model was also used as the base for a sediment transport (ST) model (as explained in the Sediment Transport Modeling section). The ST model was used to find the relative change in estuarine processes before and after construction of the Seaway. The model was also used to examine the relative effect of the canal system $v s$. that of the inlet modification (construction of Seaway) on changes in estuarine processes.

\section{Model Calibration}

Initially, the model was run for a few days to establish the tidal momentum within the estuary before calibration. Water level variations, measured simultaneously for at least 35 days (between December 2004 and January 2005) at seven stations within the study area, was used for calibration of the model. Calibration was achieved by adjusting the Manning coefficient $n$ for different sections of the model. To this end, the model was run for a number of different Manning coefficient $n$ values. The best correlation between the model and the recorded data was obtained using a combination of the Manning coefficients between 0.024 and 0.03 for various reaches of the estuary. A variable value of the Manning coefficient $n$ was adopted for each cross section, depending on the variation of roughness at various parts of the cross section. A comparison between the results from the calibrated model and the measured water level at eight locations within the study area showed very good agreement. Figure 8 shows this comparison at one of these stations (station 3 and Seven Oak). 
Table 2. Differences between the measured data and model results.

\begin{tabular}{cccc}
\hline \hline $\begin{array}{c}\text { Tidal } \\
\text { Constituents }\end{array}$ & $\begin{array}{c}\text { RMS } \\
\text { Amplitude } \\
\text { Difference }(\mathrm{m}) *\end{array}$ & $\begin{array}{c}\text { RMS Phase } \\
\text { Difference } \\
\text { (degree) }\end{array}$ & $\begin{array}{c}\text { Measured } \\
\text { Mean } \\
\text { Amplitude }\end{array}$ \\
\hline O1 & 0.005 & 4 & 0.09 \\
K1 & 0.004 & 5 & 0.18 \\
N2 & 0.001 & 2 & 0.08 \\
M2 & 0.006 & 2 & 0.41 \\
S2 & 0.004 & 3 & 0.09 \\
\hline
\end{tabular}

$*$ RMS $=$ Root mean square.

\section{Tidal Model Evaluation}

The performance of the model was measured by calculating the difference between the computed amplitudes and the phases of five major tidal constituents (O1, K1, N2, M2, and S2) from the measured values, as shown in Table 2.

Table 2 shows that the difference between the root meansquare amplitude of the tidal constituents calculated from the measured data and from the model results varied between 1 and $6 \mathrm{~mm}$. The maximum difference $(6 \mathrm{~mm})$ was associated with the semidiurnal M2 constituent. M2 constituents had the largest amplitude among all the constituents, with a mean amplitude of $0.41 \mathrm{~m}$. This resulted in less than a $1.5 \%$ discrepancy. The difference between the root mean-square phase of the tidal constituents calculated from the measured data and from the model results varied between 2 to 5 degrees.

The accuracy of the model was verified against water-level measurements at stations 1 and 4 during the period between February 2005 and June 2005 and at station 5 during the period between April 2005 and June 2005. Model verification was performed using the same Manning coefficients that were used for model calibration. The measured and simulated water levels, both in terms of magnitude and phase, were found to match very well.

\section{DATA ANALYSIS AND DISCUSSION}

\section{Tidal Condition}

At the Nerang Estuary, tidal movement is the driving force for horizontal water flow, (except during heavy storm conditions, which may occur during the wet season). Harmonic analysis of measured tide data at various locations within the estuary showed that the semidiurnal M2 constituent is the dominant component of tidal regime. The tide has an average range of more than $1 \mathrm{~m}$, which increases to $2 \mathrm{~m}$ during spring tide at lower reaches of the estuary. Maximum tidal range reduces to $1.6 \mathrm{~m}$ at the upper reaches of the estuary. Tidal characteristics at the Nerang Estuary were identified as mixed, predominantly semidiurnal using the form number as defined by Pugh (1987):

$$
\mathrm{N}=\frac{\mathrm{O} 1+\mathrm{K} 1}{\mathrm{M} 2+\mathrm{S} 2}
$$

The form number for the Nerang Estuary varied between 0.47 and 0.64 at the seven measurement stations. A form number between 0.25 and 1.5 is regarded as a mixed, semidiurnal regime.

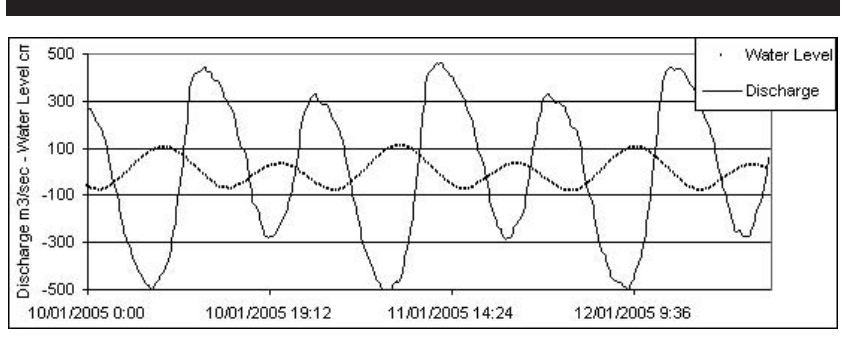

Figure 9. Discharge and water-level variations at Nerang River mouth station.

\section{Tidal Discharge}

Figure 9 shows the variations in discharge for an arbitrary 48 hours tidal cycle at the mouth of estuary. In this figure, positive values indicate ebb discharge, and negative values indicate flood discharge. Analysis of discharge and water elevations along the estuary provided the following information:

- The phase lag between peak water level and peak flood discharge typically varied between 1 hour, at the lower reaches of the estuary, and 2 hours, at the upper reaches of the estuary; the time lag between low water and peak ebb discharge varied between 3 hours, at lower reaches of the estuary, and 5.5 hours, at the upper reaches of the estuary.

- At all stations, the rate of water level rise during the flood tide was faster than the rate of water level fall during the ebb.

- Generally, the duration of ebb discharge was longer than the duration of the flood discharge.

- At all stations, the maximum flood discharge was higher than the maximum ebb discharge (flow velocity).

- Flow reversal, during high, slack water, was faster than that during low, slack water.

\section{Comparison of Tidal Discharge along the Estuary}

Figures 10 and 11 show the discharge variations over two arbitrary tidal cycles during the neap and spring tides at four stations along the Nerang River Estuary. These plots show that discharge reduced dramatically as the tide progressed

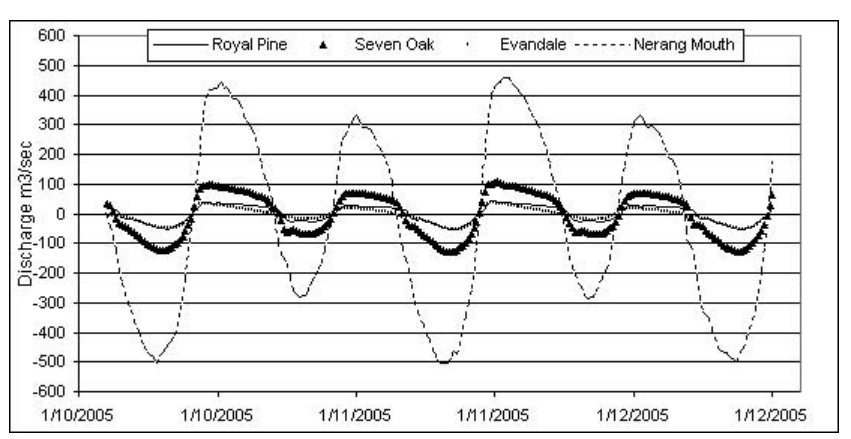

Figure 10. Comparison between discharges at various stations along the Nerang River Estuary during the spring tide period. 


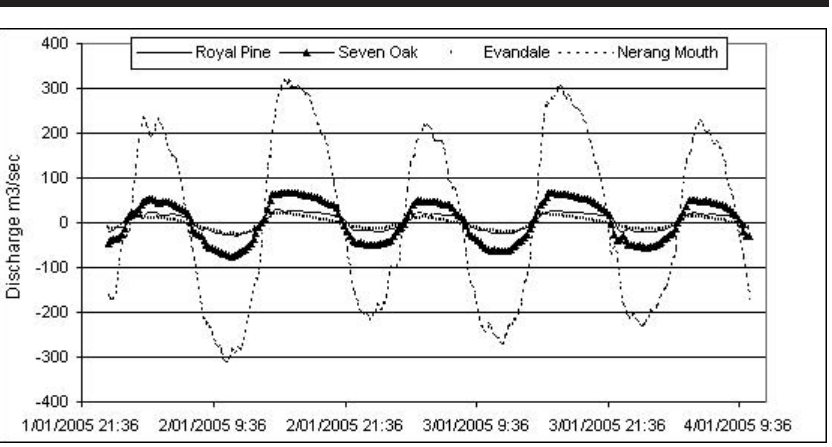

Figure 11. Comparison between discharges at various stations along the Nerang River Estuary during the neap tide period.

upstream of the estuary. At all stations, peak flood discharge was stronger than peak ebb discharge during spring tides. During neap tides, the difference between peak flood and ebb discharges became very small, indicating a stronger tidal asymmetry during the spring tide. Figure 10 shows a dramatic change in acceleration when the ebb current approached zero. Acceleration change during the ebb was smoother when the tidal range was small (Figure 11). The change in acceleration indicates that once water level goes below the mean tidal level, the effect of frictional forces becomes increasingly important and slows the ebb flow down. The maximum effect was when water depth was at its minimum. This effect was less during neap tides because the tidal range was smaller, and the minimum water depth during low, slack water was more than that during spring tide.

In general, the status of the tide in a shallow estuary reflects a balance between various forces. Such forces include influences that tend to dissipate tidal energy, such as frictional forces; forces that result in a nonlinear transfer of energy between tidal constituents, and forces that cause amplification of the tidal range because of changes in bathymetry.

Results from the numerical modelling show that tidal dissipation or amplification occurred at different rates in various sections of the estuary. Tidal range reduced by $0.2 \mathrm{~m}$ as the tide moved approximately $3 \mathrm{~km}$ upstream from the mouth of the estuary. This trend continued along the estuary for another 5 to $6 \mathrm{~km}$. An additional reduction of $0.2 \mathrm{~m}$ was observed over approximately $9 \mathrm{~km}$ upstream of the mouth of the estuary. The change in range remained relatively small for the rest of the estuary length.

The tidal range reduction over the first $9 \mathrm{~km}$ of the estuary, on one hand, could be an indication of the effect of canal estates, which are connected to the estuary over the first $9 \mathrm{~km}$ of its length. On the other hand, the reduction could be an indication that bed friction was the dominating factor in the evolution of the tidal propagation along the first $9 \mathrm{~km}$ of the estuary. Tidal range remained relatively unchanged over the rest of the estuary length, indicating a balance between dissipating and amplifying influences.

\section{Tidal Asymmetry}

In shallow estuarine waters, tidal range is comparable to average depth, resulting in nonlinear mechanisms that distort the

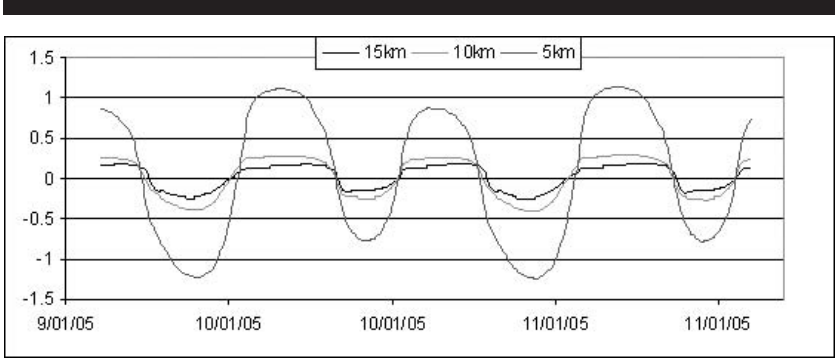

Figure 12. Velocity time history over an arbitrary $48 \mathrm{~h}$ period at 5,10 , and $15 \mathrm{~km}$ upstream from the river mouth.

tidal wave profile. One of the important nonlinear mechanisms is the generation of M2 overtides, namely M4 and M6, as a result of bottom friction and continuity constraints (Friedrichs and Aubrey, 1998; Parker, 1991; Walters and Werner, 1991). Nonlinear mechanisms can potentially have an impact on bank erosion, sediment transport regime, advection-dispersion characteristics, and ecology (Blanton et al., 2004). One of the aims of this study was to assess these impacts through harmonic analysis of the collected data and through numerical modelling of tidal flow. This assessment included an examination of historical tidal data for the study area.

One outcome of the nonlinear distortion of a tidal current is flood or ebb dominance of an estuary (Friedrichs and Aubrey, 1998; Parker, 1991). Flood dominance is seen as a shorter flood phase, with higher flow velocity and a longer ebb phase, with lower flow velocity, and vice versa in the case of ebb dominance.

Figure 12 shows the velocity time history over an arbitrary 48-hour period at three locations $(5,10$, and $15 \mathrm{~km}$ upstream from the river mouth). In general, it can be seen that flow velocity was higher during the flood phase and that the flood phase was a bit shorter than that of ebb phase. This indicates that the Nerang River is slightly flood dominant.

\section{Tidal Prism}

Tidal prism has an important effect on bed erosion, on the stability of channel banks, and on the general ecological health of an estuary. Calculation of the total volume of water moving past the throat of the Nerang Estuary (at Sundale Bridge) during the flood tide showed that the tidal prism for a typical spring tide was approximately $8,000,000 \mathrm{~m}^{3}$ for an approximate cross-section area of $1300 \mathrm{~m}^{2}$ at the mouth of the estuary.

\section{Importance of Nonlinear Mechanisms}

Estuarine processes are generally complicated by the existence of various nonlinear mechanisms, which result in the distortion of the wave profile, with serious consequences for the transport of pollution and sediment to and from tidal estuaries. Parker (1991) provides a comprehensive review of the importance of the various nonlinear mechanisms in tidal estuaries.

Figure 13 shows the three largest semidiurnal constituents along the Nerang Estuary. The amplitude of the M2 constit- 


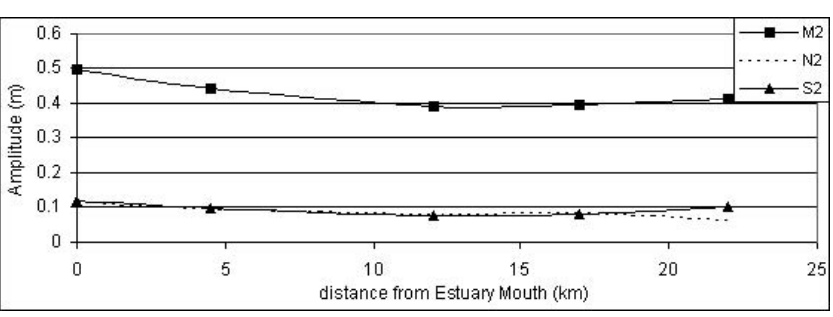

Figure 13. Amplitude variations of three largest major semidiurnal constituents at the Nerang River Estuary.

uent reduces slightly from $0.5 \mathrm{~m}$ at station 1 at the mouth of the estuary to slightly below $0.4 \mathrm{~m}$ at station 3 , approximately $12 \mathrm{~km}$ upstream of the estuary mouth. The amplitude of the M2 constituents remains relatively unchanged for the rest of the estuary length. The amplitude of the N2 constituent experiences a slight reduction (from $0.11 \mathrm{~m}$ to $0.08 \mathrm{~m}$ ) over the first $12 \mathrm{~km}$ of the estuary. It then increases steadily over the rest of the estuary length and reaches $0.1 \mathrm{~m}$, approximately $22 \mathrm{~km}$ upstream of the estuary mouth. The amplitude of the S2 constituent exhibits similar trends over the first $12 \mathrm{~km}$ of the estuary, but unlike the N2 constituent, it continues a steady reduction over the rest of the estuary length and reaches to $0.05 \mathrm{~m}$ approximately $22 \mathrm{~km}$ upstream of the estuary mouth (compared with $0.11 \mathrm{~m}$ amplitude at the mouth of the estuary).

The dissimilarity in behaviour of semidiurnal tidal constituents N2 and S2 cannot be explained in a linear context and highlights the existence of nonlinear mechanisms being active. In general, it seems that (as far as semidiurnal constituents are concerned) frictional forces, which generally result in damping the amplitude, are dominant during the first 12 $\mathrm{km}$ of the estuary length, whereas, farther from the estuary mouth, there is a balance between frictional forces and other nonlinear mechanisms that result from the interaction between the tidal wave and the river bathymetry.

Figure 14 shows the variation of the two largest diurnal constituents in the Nerang Estuary. It can be seen that the amplitude of the $\mathrm{K} 1$ component of the tide reduces from 0.21 $\mathrm{m}$ (at the estuary mouth) to $0.15 \mathrm{~m}$, approximately $22 \mathrm{~km}$ upstream of the estuary mouth. Changes in the $\mathrm{O} 1$ component amplitude are minimal. The dissimilarity of behaviour

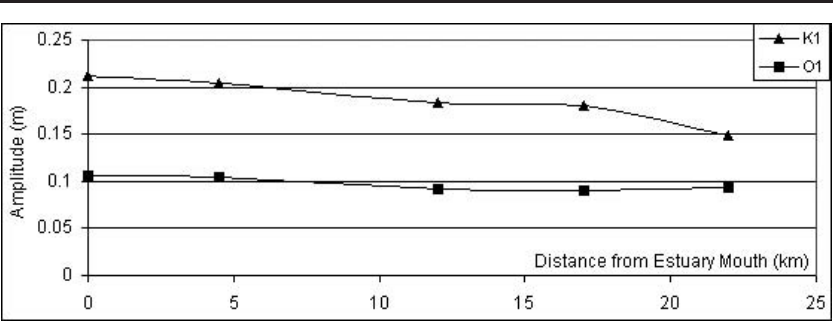

Figure 14. Amplitude variations of two largest major diurnal constituents at the Nerang River Estuary.

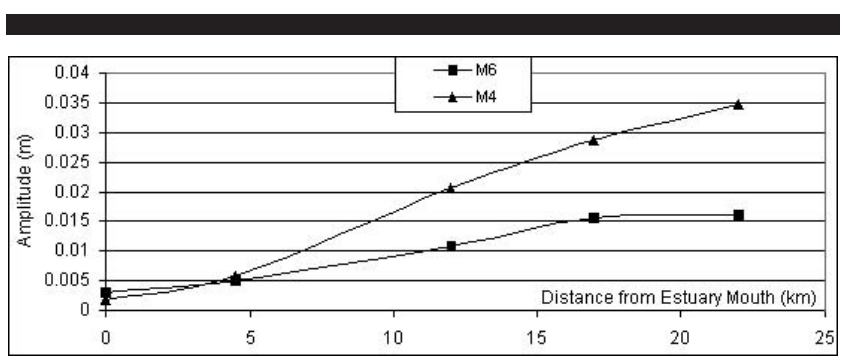

Figure 15. Amplitude variations of the M4 and M6 constituents at the Nerang River Estuary.

between these two diurnal constituents, again, highlights the importance of nonlinear mechanisms.

To highlight the relative importance of frictional dissipation and spectral energy transfer from M2 to M4 and M6 as the tide propagates in shallow waters, the variations of amplitude of the M4 and M6 components of the tide are depicted in Figure 15. The M4 constituent is generated by the nonlinear interaction of the M2 constituent with itself. The physical manifestation of M4 is the asymmetric distortion of the tide curve, which results in differences between ebb and flood current velocities. The importance of the M4 constituent is that once the bed shear stress for mobility in a tidal estuary is exceeded, even a small difference between the flood and ebb currents can result in large differences in ebb-and-flood-induced sand transport. M6 constituent is mainly generated by frictional mechanisms, and its magnitude is an indicator of the importance of frictional forces, (Parker, 1991)

Figure 15 shows that the M4 amplitude increases slowly over the first $5 \mathrm{~km}$ from the estuary mouth (from $0.2 \mathrm{~cm}$ to $0.5 \mathrm{~cm}$ ); then, it increases sharply from $0.5 \mathrm{~cm}$ to $3.5 \mathrm{~cm}$ at approximately $22 \mathrm{~km}$ upstream from the estuary mouth. The amplitude of the M6 component exhibits a steady increase over the first $15 \mathrm{~km}$ of the estuary (from $0.2 \mathrm{~cm}$ to $1.5 \mathrm{~cm}$ ) and then remains unchanged for the rest of the estuary length. To highlight the strength of the nonlinear responses of the estuary to tidal forcing, the ratio of the amplitudes of M4 and M6 to M2 has been presented in Figure 16 as the primary indicators of nonlinearity. The above-mentioned variation of M6 constituents along the Nerang Estuary corresponds to M6:M2 amplitude ratios of $1 \%, 3 \%, 7 \%, 10 \%$, and $9 \%$, respectively, at the mouth, $5 \mathrm{~km}, 12 \mathrm{~km}, 17 \mathrm{~km}$, and 22 $\mathrm{km}$ upstream of the estuary. The M4:M2 amplitude ratio

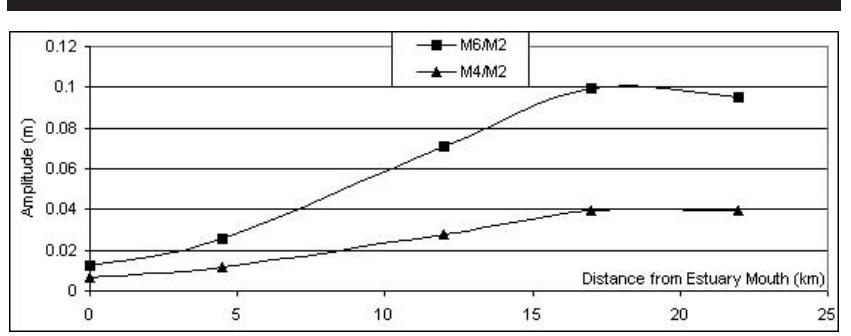

Figure 16. Amplitude variations of the M4:M2 and M6:M2 ratios at the Nerang River Estuary. 


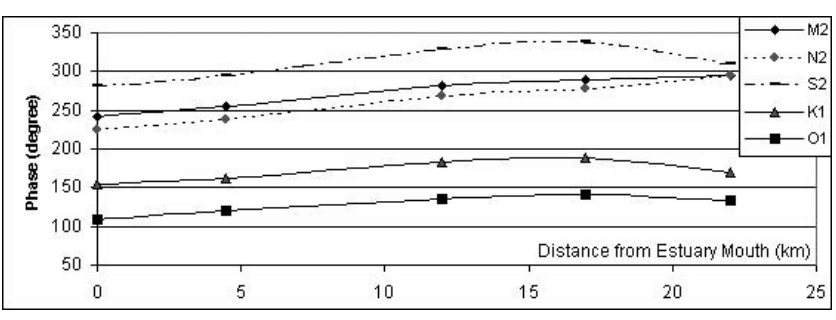

Figure 17. Phase variations associated with major tidal constituents along the Nerang River Estuary.

was $1 \%, 1.5 \%, 3 \%, 4 \%$, and $4 \%$ at similar above-mentioned locations. Both ratios (M4 : M2 and M6 : M2) increased slightly for the first $5 \mathrm{~km}$ of the estuary, followed by a relatively sharp increase over the next $12 \mathrm{~km}$, and then, remained unchanged for the rest of the length of the estuary. The growth of high-frequency M2 overtides (M4 and M6) reflects the combined frictional decay of the M2 component and also the spectral energy transfer from M2 to M4 and M6 overtides (manifested as real growth of M4 and M6 overtides). It is also evidence of the strong, nonlinear response of the estuary to tidal forcing over the first $17 \mathrm{~km}$.

Figure 16 also shows that the M6 amplitude is generally much smaller than M4, but the rate of growth of M6 is higher than M4. This indicates a stronger M6 generation than M4 generation within the estuary.

Figure 17 shows the variation of the phase of semidiurnal and diurnal constituents over the length of the estuary. Change in phase is an indication of frictional forces and the nonlinear response of the estuary. It can be seen that all constituents display relatively similar patterns: an increase of phase over the first $17 \mathrm{~km}$ of the estuary, and a slight reduction or little change over the remaining $5 \mathrm{~km}$ of the estuary.

\section{Sediment Transport Regime Potentials at the Nerang Estuary}

Tidal asymmetry and the resulting flood or ebb dominance play an important role in the sediment transport regime of an estuary. Because sediment transport is proportional to the flow velocity above a threshold to some power, the higher flood or ebb velocities can result in a net (coarse) sediment transport into or out of the estuary.

The Nerang Estuary exhibits three important hydrodynamic features: higher flood current velocity, longer ebb duration, and faster flow reversal during high, slack water. The first feature generally results in net sediment transport into the estuary, provided that the velocity exceeds the required threshold for the movement of sand. In general, coarse sands will be more affected by high current velocity.

The second feature can potentially result in net fine-sediment transport out of the estuary because fine and suspended materials are more affected by the duration of flood or ebb periods. In addition, slower flow reversal, and in consequence, longer slack water, will provide more time for fine sediments to be deposited in tidal flats (Dronkers, 1986), giv- ing rise to the possibility of extending the size of the tidal flats below mean sea level.

The net sediment transport at the Nerang Estuary depends on the balance between two opposing forces, which act on coarse and fine sediments differently. Having said that, no definitive conclusion based solely on hydrodynamic results can be drawn in regard to the sediment transport regime. As an example, although a high flood-current velocity gives rise to the expectation of net sediment transport into the estuary (at least as far as coarse sediments are concerned), the threshold velocity for the movement of sand may be below the high-ebb current velocity. In that case, the duration of time that the velocity is above the threshold is important, and despite higher flood-current velocity, a seaward sediment-transport regime may prevail. The subject of the sediment transport is dealt with in the Sediment Transport Modeling section.

\section{Evolution of Tidal Regime during the Past 20 Years}

This section provides an overview of the evolution of the tidal regime during the past 20 years. The tide data used in this section, apart from data collected by the authors in 2005, were provided by the Queensland Department of Transport (Broadbent, 1988). As part of this study, harmonic analysis of tidal data was conducted, using Mike21 (DHI, 2005) software platform, which is based on IOS tidal package methodology. The aim of this analysis was to resolve the tidal dynamics of the estuary during the past 20 years.

Figures 18a-i show the variations of semidiurnal constituents (N2, M2, and S2); diurnal constituents (O1 and K1); and the ratio of M4:M2 tidal constituents of the Nerang Estuary during the past 20 years. Construction of the Gold Coast Seaway started in 1985, and the associated dredging work was completed in 1986. Except at the location of station 5 , there is no information on tidal variation within the Nerang Estuary before the start of construction of the Seaway.

Figure 18a shows an approximate $30 \%$ increase in the amplitude of M2 and N2 constituents between 1986 (after construction of the Seaway) and 2005. The S2 constituent appears to have risen slightly, immediately after the construction of the Seaway, and then fallen back for both stations. Figure $18 \mathrm{~b}$ shows that $\mathrm{O} 1$ and $\mathrm{Q} 1$ constituents rose slightly after the construction of the Seaway and then fell back. The figure shows more than a $30 \%$ increase in the amplitude of $\mathrm{K} 1$ by year 2005 . Figure $18 \mathrm{c}$ shows a drop in the M4 : M2 ratio after the construction of the Seaway at station 1 (60\% reduction). Tidal measurements in 1998 and 2005 show that this ratio has declined continuously (70\% reduction in 1998 and $95 \%$ in 2005).

Figure 18d shows more than a $30 \%$ increase in the amplitude of M2 and N2 constituents as a result of the construction of the Gold Coast Seaway. The S2 constituent appears to have risen slightly, immediately after the construction of the Seaway, and then fallen back for both stations. Figure 18e shows that $\mathrm{O} 1$ and $\mathrm{Q} 1$ constituents have risen slightly after the construction of the Seaway and then fallen back. The figure shows more than a $50 \%$ increase in the amplitude of $\mathrm{K} 1$ by year 2005 . Figure $18 f$ shows a $250 \%$ reduction of the M4: 

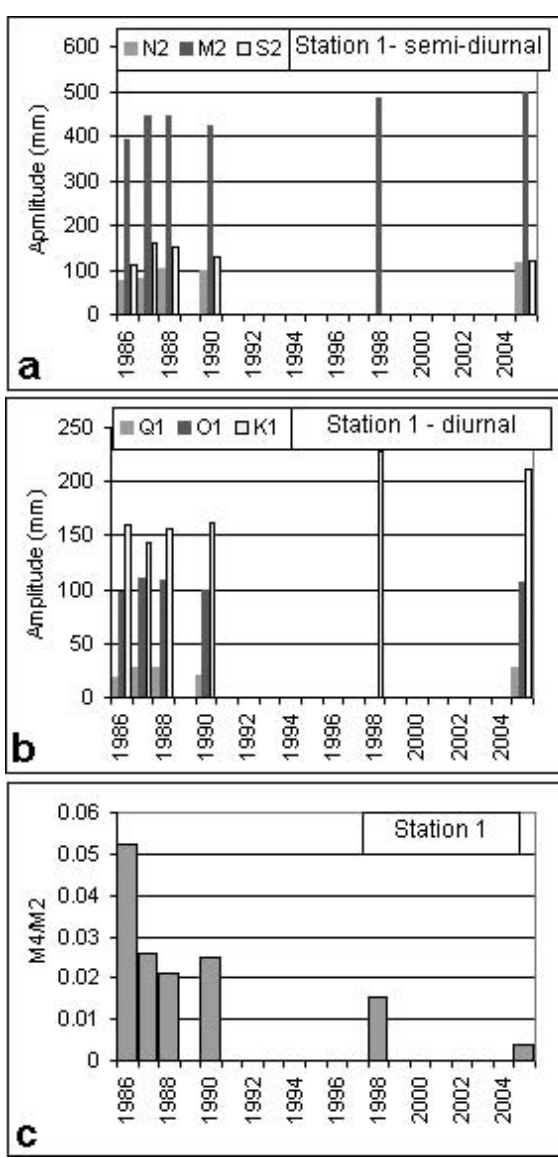
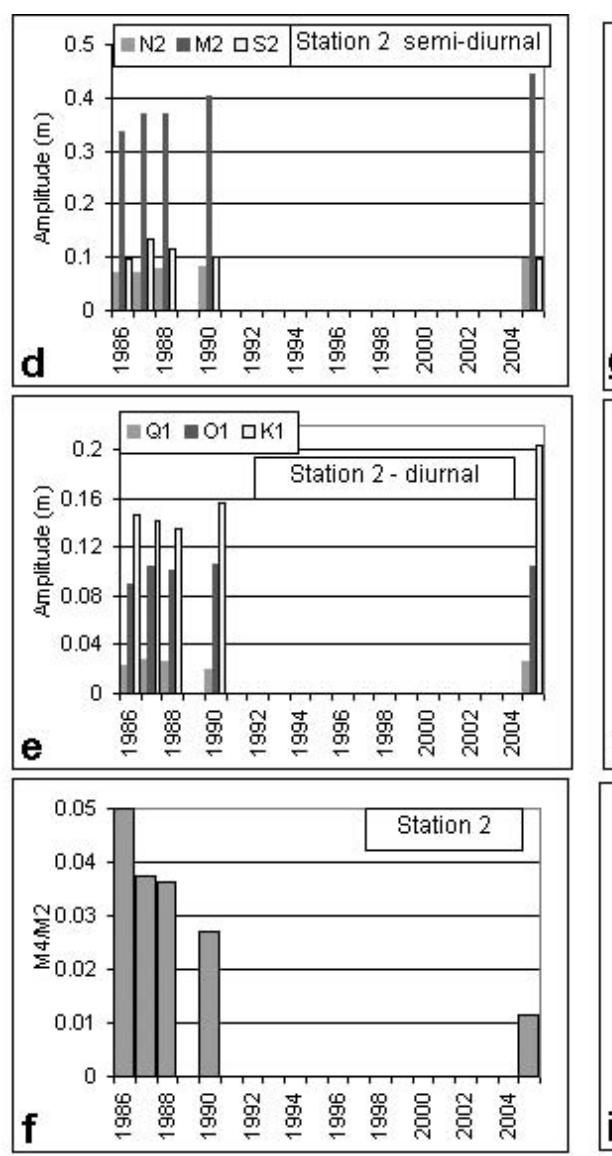
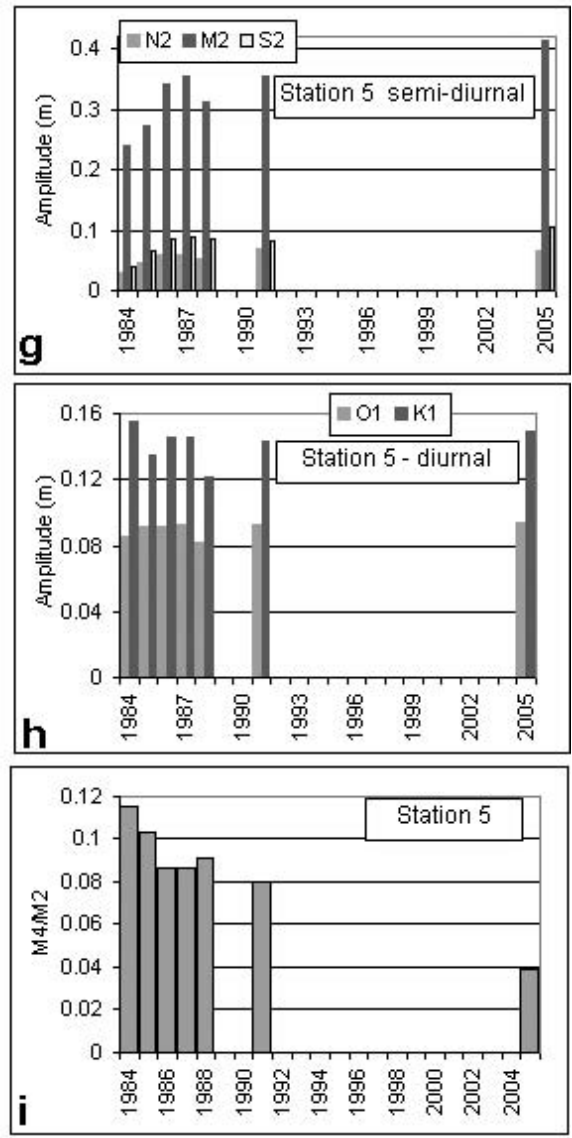

Figure 18. Historical variation of tidal dynamic at the Nerang River Estuary for a) station 1, semi-diurnal constituents b) station 1, diurnal constituents, c) station 1, M4/M2, d) station 2, semi-diurnal constituents e) station 2, diurnal constituents, f) station 2, M4/M2, g) station 5, semi-diurnal constituents g) station 5, diurnal constituents i) station 5, M4/M2.

M2 ratio at station 2 after the construction of the Seaway. This reduction continued to $1000 \%$ by year 2005 .

Tidal analysis of water level variations at station 5 (Figure $18 \mathrm{~g}$ ) shows a $45 \%$ increase in the amplitude of M2 constituents between 1984 and 1986 (before start of construction and after completion). The increase continues for the next 20 years, reaching to $0.43 \mathrm{~m}$ in 2005 , more than $20 \%$, more than its value in 1986, and $75 \%$ of its value in 1984 . This trend can also be observed for S2 constituents. S2 amplitude increases $110 \%$ between 1984 and 1986 and reaches $0.11 \mathrm{~m}$ (approximately 20\% more than its value in 1986) in 2005. The N2 constituent shows a similar trend between 1984 and 1986 (110\% increase in amplitude). Unlike the M2 and S2 constituents, the N2 constituent experienced only minor variations during the 20 year period. Figure $18 \mathrm{~h}$ shows that variations of the diurnal constituents have been minimal during that period of time. Figure 18i shows that the M4:M2 ratio experienced an opposite trend compared with that of semidiurnal constituents. This ratio reduces almost $33 \%$ between 1984 and 1986. It remains relatively unchanged until 1991, but measurement in the year 2005 shows a further $120 \%$ decrease since 1991.
These results clearly show that tidal asymmetry and nonlinear responses of the Nerang River Estuary have been reduced during the past 20 years. They also indicate an increase of tidal range throughout the estuary and for most of the tidal spectrum. These changes can, potentially, have a substantial impact on the morphology and ecology of the estuary.

\section{Flood and Ebb Dominance Status of the Nerang Estuary during the Past 20 Years}

One of the outcomes of the nonlinear distortion of the tidal current is flood or ebb dominance of the estuary. Aubrey and Speer (1985) showed that whether an estuary is flood-dominant or ebb-dominant depends on the phase difference $2 \theta_{\mathrm{M} 2}$ $-\theta_{\mathrm{M} 4}$ where $\theta$ is the phase of tidal height. A $90^{\circ}$ phase difference of tidal height means shorter flood durations (compared with ebb durations). This results in a higher flood-current velocity and, consequently, a flood-dominant situation. A $270^{\circ}$ phase difference of tidal height means longer flood duration, which can result in a higher ebb-current velocity than flood current velocity. Aubrey and Speer (1985) and Friedrichs and Aubrey (1988) conducted theoretical and field- 
Table 3. Variations of phase difference between M2 and M4 components over time.

\begin{tabular}{ccccc}
\hline \hline & \multicolumn{4}{c}{$2 \theta_{M_{2}}-\theta_{M_{4}}$ (degree) } \\
\cline { 2 - 5 } Year & Station 1 & Station 2 & Station 5 & Type \\
\hline 1984 & & & 76 & Flood dominance \\
1985 & & & 82 & Flood dominance \\
1986 & 103 & 101 & 78 & Flood dominance \\
1987 & 101 & 97 & 73 & Flood dominance \\
1988 & 114 & 97 & 74 & Flood dominance \\
1991 & & & 75 & Flood dominance \\
2005 & 177 & 76 & 64 & Flood dominance \\
\hline
\end{tabular}

work on tidal asymmetry for estuaries with semidiurnal tidal regime. Based on their study, under a semidiurnal regime, an estuary has flood-dominant current when

$$
0^{\circ}<2 \theta_{\mathrm{M} 2}-\theta_{\mathrm{M} 4}<180^{\circ}
$$

and ebb-dominant current when

$$
180^{\circ}<2 \theta_{\mathrm{M} 2}-\theta_{\mathrm{M} 4}<360^{\circ} \text {. }
$$

Table 3 shows that the tidal regime at the Nerang Estuary has been predominantly semidiurnal with the value for Equation (2) being between $0^{\circ}$ and $180^{\circ}$, indicating a flood-dominant tidal asymmetry throughout the estuary during the past 20 years.

\section{Sediment-Transport Implications Resulting from Tidal Asymmetry Variations at the Nerang Estuary}

The ratio of amplitude of M4 to M2 has been used as an indicator of the degrees of nonlinear response to tidal forcing. Variations in the ratio of amplitudes of M4 to M2 (shown in Figures 18c, 18f, and 18i) demonstrate that the Nerang Estuary has had reducing degrees of nonlinear response to tidal forcing during the past 20 years. The nonlinear spectral transfer from M2 to M4 and phase difference between these two components will have a minor impact on the decay of the M2 amplitude (and as a result, decay of the tidal range), but it can have a substantial impact on sediment-transport characteristics of the estuary.

A strong M4, associated with a phase lead between $0^{\circ}$ and $180^{\circ}$ (with respect to the M2 phase) results in a distorted water surface, with a shorter rising tide period than falling tide period (Aubrey and Speer, 1993). This results in an asymmetric tide and a flood-dominant situation with a stronger flood than ebb flow velocity.

In terms of sediment transport, this can result in having more sediment transported into the estuary during the flood tide than transported out of the estuary during the ebb tide. Net sediment transport at the Nerang Estuary depends on the balance between tidally influenced sediment infilling of the estuary against flood-induced sediment flushing out of the estuary. A reduction in the strength of the $\mathrm{M} 4: \mathrm{M} 2$ ratio, and also, the departure of the M4 phase lead from $90^{\circ}$ during the past 20 years indicates a less-asymmetrical tidal condition and, therefore, a less flood-dominant estuary at present than 20 years ago. This can be regarded as evidence that the net sediment-transport regime may have shifted toward hav-

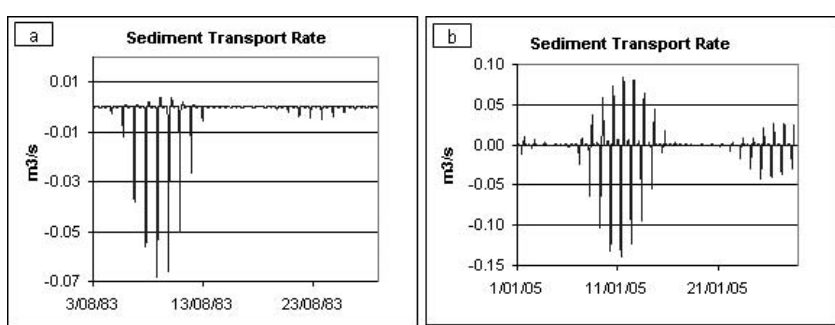

Figure 19. A comparison between sediment-transport rates in the years (a) 1983 and (b) 2005, $7 \mathrm{~km}$ upstream of the Nerang River mouth.

ing more net sediment movement out of the estuary during the past 20 years. This is consistent with extensive sandbar growth just outside the Nerang River Estuary within the Broadwater during the past 20 years, despite the number of flooding events during this period having been far less, compared with the years before construction of the Seaway.

\section{Sediment-Transport Modelling}

A one-dimensional sediment-transport model was set up, based on the calibrated hydrodynamic that was explained above) to simulate the sediment-transport regime within the study area, The model is based on the Engelund and Fredsoe (1976) transport model and was run in a morphological mode, meaning that the bed level is updated at every time step while running the hydrodynamic and sediment transport models in tandem. In this exercise, bed material was represented by uniform grain-size sand of $0.2 \mathrm{~mm}$, which is a representative grain size diameter for the study area. This model was very basic (without any rigorous calibration of the sediment movement) and provided a highly stylised representation of the before-tide patterns (before construction of the Seaway). The model results, however, gave support for the circumstantial evidence provided by sand bar growth in the Broadwater and allowed examination of the relative importance of the influencing parameters in tidal (sediment transport) regime change. The model was run for a period of 1 month in years 1983 (before construction of the Seaway) and in 2005 . The model was driven by the measured tidal data in corresponding years. Figure 19 shows a comparison between sediment transport-rates at a representative station, approximately $7 \mathrm{~km}$ upstream of the river mouth, during 16 days covering spring and neap tide phases. The negative values indicate the sediment-transport rate during the flood tide, and the positive values correspond to the ebb tide. The figure clearly shows that the ratio of ebb sediment-transport rate to flood sediment-transport rate is far greater in year 2005 than in 1983. Calculation of the total sediment transported at this station shows that the volume of sediment transported out of the estuary during ebb tides is less than $10 \%$ of that transported into the estuary during flood tides in year 1983. This ratio had increased to $80 \%$ in year 2005 , indicating a far less flood-dominant estuary. To examine the impact of canal developments in this process, the largest water body of the system-the Burleigh Lakes Canal Estate-was removed from 
the model. This change had little impact on the above-mentioned ratios, indicating that the construction of the Seaway dominates the tidal regime, and hence the sediment-transport regime, within the study area.

\section{Biological Implications Resulting from Tidal Asymmetry and Tidal Asymmetry Variations}

The biology of the estuary can be affected by the construction of the Seaway in different ways. Many of the benthic and planktonic species within the estuarine environment have been adapted to the level of salinity, residual currents, tidal strength, duration of low and high slack waters, and verticalmixing characteristics over very long periods of time. As an example, higher flood tidal currents will transport organisms into shallower, less-dense waters at the upstream reaches of the estuary; slack-water duration will determine their residence time at various reaches of the estuary; and verticalmixing strength will provide them with upstream-transport opportunities. Changes in discharge, flow velocity, and the asymmetric nature of the tide has resulted in all the hydrodynamic features of an estuary undergoing substantial changes during the past 20 years. The impacts from these changes are yet to be fully explored. A more thorough investigation of the biological implications within the Nerang Estuary is the subject of the next stage of this study.

\section{CONCLUSION}

It has been concluded that

- The Nerang Estuary has had a mixed, predominantly semidiurnal, tidal regime during the past 20 years;

- The tidal regime within the estuary is temporally asymmetrical;

- The tidal range is between $2 \mathrm{~m}$ (at the lower reaches of the estuary) and $1.6 \mathrm{~m}$ at the upper reaches of the estuary;

- The tidal-range reduction occurs mainly during the first 9 $\mathrm{km}$ of the estuary length;

- The estuary is flood dominant throughout its entire length and has been so during the past 20 years;

- The estuary responds nonlinearly to tidal forcing, and the strength of this nonlinear response increases at the upper reaches of the estuary; and

- Both semidiurnal and diurnal components of the tide undergo dissipation during the first $12 \mathrm{~km}$ of the estuary length, indicating friction dominance through this portion of the estuary. The M4 component is amplified throughout the entire length of the estuary, with an increased rate toward the upper reaches, indicating an increasing energy transfer from M2 constituents to its overtides as the tide progresses toward the upper reaches of the estuary.

As a result of a range of development projects, such as tidal-entrance stabilization and dredging at lower reaches of the estuary

- The Nerang Estuary appears to have become less flood dominant during the past 20 years;

- The estuary has undergone a reducing, nonlinear response to tidal forcing during the past 20 years; and
- The tidal range has been increasing within the estuary, and as a result, the volume of water, the discharge, and the current velocity within the estuary have changed.

These impacts have

- Possibly shifted the net sediment-transport balance at the Nerang Estuary toward having less sand transported into the estuary,

- Increased the tidal range,

- Increased salinity intrusion, and

- Changed the flow dynamics, with some impact on the ecology of the estuary.

\section{ACKNOWLEDGMENTS}

Financial support for this project has been provided by the Gold Coast City Council (Economic Development and Major Project Directorate) and Griffith University. We wish to thank Ms. Zoe Ford and Mr. Darren Stewart, from the Gold Coast City Council, Mr. Lawrence Hughes, from Griffith University, and Mr. John Broadbent, from the Maritime Safety Queensland, for their help and support throughout this project. We gratefully acknowledge the contribution of Dr. Charles Lemckert, from the Engineering School of Griffith University, for providing the project team with the required equipment and support for measurements.

\section{LITERATURE CITED}

Aubrey, D.G. and Speer, P.E., 1985. A study of non-linear tidal propagation in shallow inlet/estuarine systems, part I: observations. Journal of Estuarine, Coastal and Shelf Science, 21(2), 185-205.

Blanton, O.J.; Verity P.G.; Amft, J.; Wenner, E.L.; Barans, C.A.; Knott, D.M.; Stender, B.W., and Wilde, S.B., 2004. Key Factors Influencing Transport of White Shrimp Postlarvae in Southeastern U.S. Estuaries: Final Report to Georgia Sea Grant Program and South Carolina Sea Grant Consortium. Savannah, Georgia: Skidaway Institute of Oceanography.

Broadbent J. 1987. Water Level Monitoring Report-The Broadwater/Nerang River. Queensland, Australia: Department of Harbours and Marine, Marine Operation Division, Tidal Sub-Section.

Broadbent J. 1988. Water Level Monitoring Report-Supplement to the Broadwater/ Nerang River. Queensland, Australia: Department of Harbours and Marine, Marine Operation Division, Tidal Sub-Section.

Danish Institute Hydraulic (DHI). MIKE 21 C State-of-the-Art River Morphology Modeling. www.dhigroup.com (accessed January 3, 2005).

Dronkers, J., 1986., Tidal asymmetry and estuarine morphology. Netherlands Journal of Sea Research, 20(2/3), 117-131.

Engelund, F. and Fredsoe, J., 1976. A sediment transport model for straight alluvial channels. Nordic Hydrology, 7(5), 293-306.

Friedrichs, C.T. and Aubrey, D.G., 1988. Non-linear tidal distortion in shallow well-mixed estuaries: a synthesis. Journal of Estuarine, Coastal and Shelf Science, 21, 185-205.

Hinwood, B.J. and Mclean, E.G., 2000. Monitoring and modelling tidal regime changes following inlet scour. Journal of Coast Research, Special Issue No. 34, pp. 449-458.

Parker, B.B., 1991. The relative importance of the various nonlinear mechanisms in a wide range of tidal interactions (review). In: Parker, B.B. (ed.), Tidal Hydrodynamics. New York: J. Wiley and Sons, pp. 237-268.

Pugh, D.T., 1987. Tides, Surges, and Mean Sea-Level. Chichester, U.K.: J. Wiley and Sons, 486p.

Walters, R.A. and Werner F.E., 1991. Nonlinear generation of overtides, compound tides and residuals. In: Parker, B.B. (ed.) Tidal Hydrodynamics. New York: J. Wiley and Sons, pp. 297-320. 